\title{
The Norwegian Statistical Association
}

Ørnulf Borgan (University of Oslo, Norway) and Marie Lilleborge (Cancer Registry of Norway, Oslo, Norway)

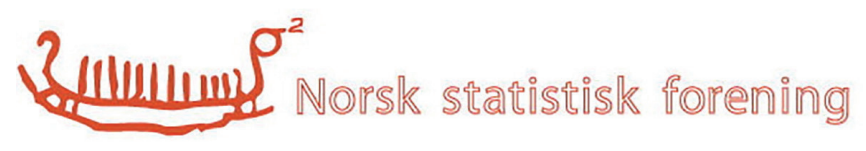

The Norwegian Statistical Association was founded 83 years ago, on April the 28th, 1936. The association actually has roots going back 100 years; it is the continuation of a club for statisticians founded on January the 7th, 1919. The first president of the Norwegian Statistical Association was Professor Ingvar Wedervang, a Norwegian economist and statistician. Professor Wedervang, together with the later Nobel laureate Ragnar Frisch, was a founder of the Department of Economics at the University of Oslo in 1932. He was also a co-founder, and the first rector, of the Norwegian School of Economics, which was also established in 1936 in Bergen as Norway's first business school.

Until 1985, The Norwegian Statistical Association was mainly an association for statisticians, economists and others working at The Central Bureau of Statistics in Oslo (now Statistics Norway). Then the association was reorganised as an association for all Norwegian statisticians, and today the majority of its about 300 members have a university degree in statistics.

The main goal of the Norwegian Statistical Association is to connect Norwegian statisticians, work for their professional interests and promote research in statistics and statistics in schools and society. The association also aims to strengthen the relationship between statisticians from the Nordic countries and increase contact with the international statistical community. The association is a member of the European Mathematical Society (EMS), the International Statistical Institute (ISI) and the Federation of European National Statistical Societies (FenStatS).

Together with its Nordic sister associations - the Danish Society for Theoretical Statistics, the Finnish Statis-

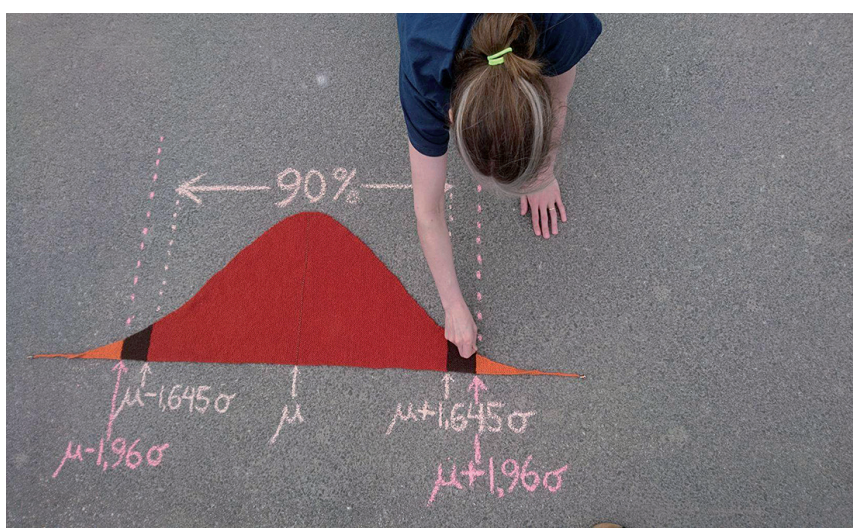

At the Norwegian Statistical Meeting in 2017, theoretical work as well as knitted normal distributions were presented. Kathrine Frey Frøslie is the author of the popular science knitting blog Statistrikk. (Photo: Ingeborg Frey Frøslie) tical Society, and the Swedish Statistical Society - the Norwegian Statistical Association is responsible for publication of The Scandinavian Journal of Statistics (SJS), and the editors in chief for the journal circulate among the four Nordic countries. The Scandinavian Journal of Statistics was founded in 1974, and it is internationally recognized today as one of the world's leading statistical journals. At the start, the journal was published by the Swedish publisher Almqvist and Wiksell, but since the early 1990s it has been published by international publishers; first Blackwell and then Wiley. The Scandinavian Journal of Statistics has four issues per year, and as of today, more than $80 \%$ of its submissions are from outside of Scandinavia.

The four Nordic statistical associations also collaborate on the organisation of the Nordic Conferences in Mathematical Statistics (NORDSTAT). The first of these biennial conferences took place in Aarhus in Denmark in 1965, and the site of the conference circulates among the four Nordic countries. Since 2008, the Baltic countries also take part in the organisation of the NORDSTAT conferences, and NORDSTAT2008 and NORDSTAT2018 took place in Lithuania and Estonia, respectively.

The Norwegian Statistical Association has three local chapters, located in Oslo, Bergen and Trondheim; corresponding to the three largest universities in Norway. The chapters have their own boards, and organize seminars and social events for their members. The chapters also take turns in organising the biennial Norwegian Statistical Meetings.

The Norwegian Statistical Meetings usually last for three days, with invited speakers and scientific contributions by $\mathrm{PhD}$ and master students and researchers. The meetings serve as a meeting point for statisticians from all over Norway. Most presentations are held in Norwegian, with slides in English. This is contrary to university seminars in Norway, where all presentations and discussions are currently held in English. The Norwegian Statistical Meetings are also the arena of the general assembly of the Norwegian Statistical Association, and the board of directors of the association is elected at these meetings. The next Norwegian Statistical Meeting will be held in Sola outside Stavanger this summer, June the 17th-20th 2019.

The Norwegian Statistical Association issues two awards. They are named after the Norwegian statistician Erling Sverdrup, who played an instrumental role in building up and modernising the fields of mathematical statistics and actuarial science in Norway. The creation of the two prizes was announced in 2007. The two Sverdrup Prizes are given to "An eminent representative of the statistics profession" and to "A young (<40 years) stat- 


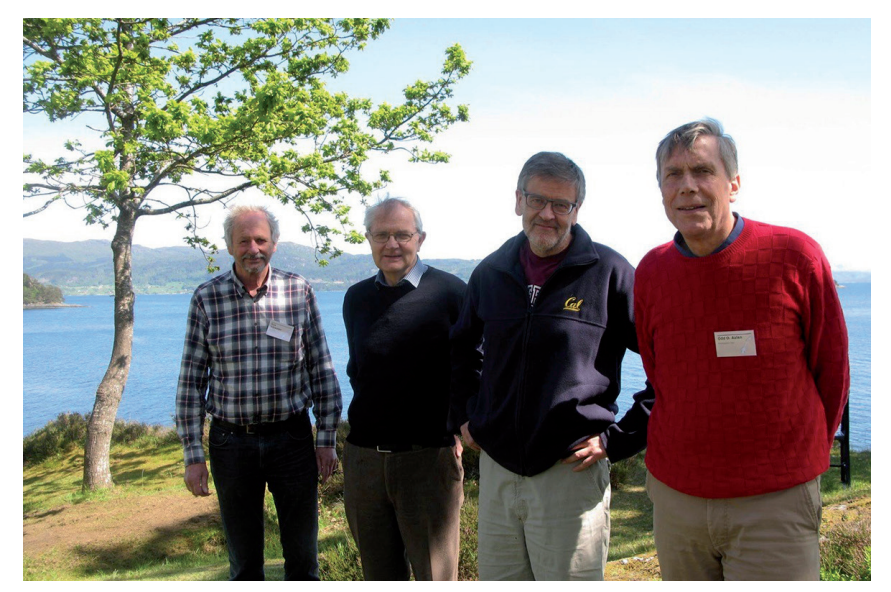

Four winners of the Sverdrup Prize for an eminent representative of the statistics profession, from left to right: Tore Schweder, Dag Tjøstheim, Nils Lid Hjort and Odd Aalen. (Photo: Celine Marie Loken Cunen)

istician with best journal article". The prizes have been awarded every second year since 2009. The winners of the prize for an eminent representative of the statistics profession have been Dag Bjarne Tjøstheim (2009), Tore Schweder (2011), Nils Lid Hjort (2013), Odd Olai Aalen (2015) and Ørnulf Borgan (2017). The winners of the young statisticians prize have been Sara Martino (2009); Ida Scheel (2011), Ingrid Hobæk Haff and Kjetil Røysland (2013); Tore Selland Kleppe (2015) and Geir-Arne Fuglstad (2017).

The Norwegian Statistical Association publishes its own member magazine in Norwegian called Tilfeldig Gang (Random Walk). Since the beginning in 1984, it has served as a newsletter for members of the associa- tion, with 2-4 issues per year. All current and historical issues are available online for free on the webpage of the association.

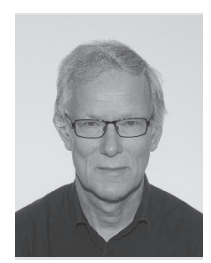

$\emptyset$ rnulf Borgan has been a professor of statistics at the University of Oslo since 1993. His main research interest is survival and event history analysis, and he is co-author of the monographs "Statistical models based on counting processes" (Springer, 1993) and "Survival and event history analysis: a process point of view" (Springer, 2008). Borgan has been editor-in-chief of Scandinavian Journal of Statistics (2007-2009) and associate editor of Annals of Statistics (1998-2003). In 2017, he was awarded the Sverdrup prize for an eminent representative of the statistics profession. Borgan is an elected member of the Norwegian Academy of Science and Letters and a fellow of the American Statistical Association.

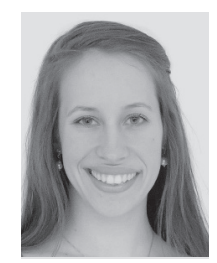

Marie Lilleborge is the second female president of the Norwegian Statistical Association, and currently a PostDoc at the Cancer Registry of Norway. Her research interests include probabilistic graphical models, algorithms and data analysis. She received her MSc degree in Industrial Mathematics at the Norwegian University of Science and Technology in 2012, and her PhD in Statistics at the University of Oslo in 2017. 